\title{
Identification and Mitigation of Waste Construction Project Material (Case Study of Building Projects in Badung Regency)
}

\author{
I G A I Mas Pertiwi ${ }^{1}$, W Sri Kristinayanti ${ }^{2}$, K Wiwin Andayani ${ }^{3}$, AA Putri Indrayanti ${ }^{4}$ \\ Civil Engineering Departement \\ Bali State Polytechnic \\ Bali, Indonesia \\ ${ }^{1}$ maspertiwi72@yahoo.co.id, ${ }^{2}$ yantie_5977@yahoo.com, ${ }^{3}$ wiwin.andayani74@yahoo.co.id, ${ }^{4}$ ajung_putri@yahoo.com
}

\begin{abstract}
Construction projects contribute to the damage to nature, among others, from material extraction, material processing, material distribution, construction processes, land acquisition for buildings and energy consumption in building operations. Besides that, construction activities also produce high enough waste. One of the discussions to overcome the problem of global warming and construction waste is to promote sustainable construction or what is often referred to as sustainable construction. In the green construction concept, one of the things that needs to be considered is waste management. The purpose of this study is to determine construction activities that have the potential to cause the construction material residuals that arise in construction projects and analyze mitigation actions to minimize the occurrence of material waste. The methods used for data collection are field observations, interviews and questionnaires. Data analysis uses qualitative analysis to determine dominant activities as a cause of waste material and mitigation actions that can be done. The results of the study stated that the activity as a potential factor causing potential waste material in building construction projects in Badung regency which most often occurred was "lack of skilled labor" with a mean value of 4.22 while the activity as the causative factor that had the greatest impact on influence was "quality material does not match specifications "with a mean value of 1.51 . From the waste risk matrix, it is found that "lack of skilled labor" is included in the category of very high waste risk due to the frequency that often occurs so that it is a very serious disruption to project implementation and corporate finance.
\end{abstract} risk

Keywords: waste material; dominant activity; risk matrix; high

\section{INTRODUCTION}

\section{A. Background}

In the implementation of a building construction project, the emergence of residual construction materials or commonly known as waste materials cannot be avoided. The rest of the construction material is defined as something that is of an excess nature than is required either in the form of work or construction material remaining/scattered /damaged so that it cannot be used again according to its function, [1]. Many factors are the source of the occurrence of construction material waste, including design, material procurement, material handling, implementation, residues and others such as theft, [2]c. Material as an important component that has a close enough influence on the cost of a project, so that with the remaining large construction material it can be ascertained that there will be swelling in the financing sector. The rest of the construction material can increase the quantity of municipal waste which is not enough for large cities. As a result the environmental burden is increasing. This is compounded if the remaining construction material contains materials that are harmful to the environment such as heavy metals, poly aromatic hydrocarbons (PAHs), etc.

The emergence of waste is a loss, especially for the implementing contractor. For this reason, it is better for each project, especially large-scale projects to have a Waste Management Plan. So that it can reduce the number of losses caused by the presence of waste material. One of the steps in the Waste Management Plan is to identify the waste material in the project location. Identification is done to find out the material that has the potential to be waste, knowing activities that can cause material waste, and knowing how much the costs of losses are caused by the occurrence of waste costs. Waste on construction projects shows considerable figures such as data from research in the Netherlands indicating that $9 \%$ of total material purchases end up as waste, and $1 \%-10 \%$ of the purchase of each material lives in the project site as waste [3]. From studies in Palestine, 5\%-11\% of material purchases are not used properly and end up as waste [4]. But before doing waste management, it is necessary to identify the waste in the construction project, find out the causes and the sources so that they can determine the steps in overcoming the waste that will occur in the future.

\section{B. Problem Formulation}

Based on the background above, several problems in this study can be formulated as follows:

- What activities do the dominant building construction projects cause waste?

- What activities have a high risk of causing waste? 
- Are mitigation actions taken against the causes of very high risk of material waste to reduce waste?

\section{Research Purposes}

Based on the above background, the purpose of this study is:

- Identifying activities in building construction projects that cause waste.

- Identifying high-risk activities that cause waste

- Determine mitigation measures against the causes of very high risk of material waste to reduce waste.

\section{LITERATURE REVIEW}

\section{A. Waste Material and Problems}

Waste can be interpreted as loss or loss of various resources, namely material, time (which is related to labor and equipment) and capital, caused by activities that require direct or indirect costs but do not add value to the final product for the parties construction service users [5]. In the implementation of construction projects, sometimes the use of material in the field does not escape mistakes and carelessness. Errors and carelessness in material problems are commonly known as waste materials, which often arise and are difficult to avoid. Waste, of course, cannot be left alone because it can disrupt the overall development process. This is due to the fact that it will take a lot of space in the limited project area, so it needs serious handling, which of course this will further increase the overall project costs because the transportation costs of the waste to the disposal area are generally quite large considering the considerable distance. From handling the waste, it will be seen which waste can be reused, recycled, sold, or discharged [6]. Some of the causes of waste material in a construction project [7] are excessive consumption of power plant, design merging and deepening of several buildings, material damage due to handling or shipping errors, material damage due to weather and improper storage, lack of material data collection sent and used, waste from the project office, and excess material from preparation and finishing work. The building or construction industry also involves a different process and uses large amounts of resources. This process has a negative impact on the environment, according to [8], occurs at various time frames from the extraction and processing of raw materials used in construction, throughout the construction process, the operation of buildings, to finally dismantling the structure at the end of its operational life. construction project activities that have the potential to generate waste, then we must know the factors that cause the waste material.

\section{B. Factors that cause waste material}

Waste material can occur in several construction projects, not only due to activities or construction activities but can also be caused by external factors such as damage or error. These external factors generally affect the amount of waste. But it is still unclear whether the waste generated comes from external factors only.

Resources that can cause waste material to occur in construction are divided into six categories [3], namely: design, material procurement, material handling, implementation, residuals, and others.

\section{Waste in Project Contruction}

Construction can be defined as activities that involve the creation of physical infrastructure, superstructure, housing and other related facilities [9]. The physical substance of a structure is a collection of materials from widely distributed sources. They undergo various types and levels of processing in a large number of places, require many types of handling during very varied periods, and use the services of many people who are organized into various types of business entities. Construction Waste can be divided into three basic groups, namely labor, materials, and equipment / mechinery. In his research on waste [10] divides waste in five groups, namely repair work, waiting time, material, human resources, and operations. Waste in construction is not only focused on the amount of waste from material in the project, but also related to waste of time [11]. Waste on construction is also related to every activity such as excess production, waiting time, material handling, process, storage and placement of workers [5]. Based on research that has been done [10] states that the main waste category in the construction field is reworks / repairs, damaged / defective, material waste, delays, waiting, poor material allocation, unnecessary material handling, unnecessary movement or movement, inaccuracy in the selection of work methods, and equipment management. According to Alwi [10], the construction waste can be in the form of Physical Construction Waste and NonValue-Adding Activity that occurs in all construction industries irrespective of: the size of the project organization, the size and duration of the contract, type of building and state of the building (construction of new or renovated buildings or in care). While the material used in construction can be classified into two major parts [2], namely:

- Consumable material, is a material that will eventually become part of the physical structure of the building, for example: cement, sand, gravel, brick, steel reinforcement, steel, and others.

- Non-consumable material, is a supporting material in the construction process, and is not a physical part of the building after the building is completed, for example: scaffolding, formwork, and temporary retaining walls.

Project activities and material types that have the potential as waste can be minimized if we know the factors that cause it and its impact on the environment and its economic value, so that the loss of project costs can be prevented or minimized.

\section{Mitigation of Waste Material}

Waste on construction projects has its own impact on every construction process [12]. The impact caused by waste affects the environment at this time and in the future. 
Therefore, efforts are needed to minimize the occurrence of waste, although waste will surely occur, but at least it can be minimized. The storage of resources and the reduction of waste are increasingly important things to consider in a sustainable construction sector. Minimizing waste means avoiding, eliminating or minimizing waste at the source of the cause, or using / recycling waste for useful and safe purposes [13]. Efforts to reduce waste at its source in building construction involve both design and technology concepts and material selection [14]. Prefabrication has been established as a solution to reduce waste generation at the design and construction stages. Prefabrication is a process carried out by a unit which is usually located in a particular place where various kinds of material are processed and combined into one to form the components which will then be installed [15]

\section{RESEARCH METHODOLOGY}

\section{A. Research Design}

This waste material construction research was carried out on building projects in Badung Regency. The study location is a building construction project that is ongoing or in the implementation stage. The study begins with data collection through field observations, interviews and questionnaires to identify the type of waste material in construction projects and activities on projects that cause material waste. For questionnaires, respondents included Site Manager, Supervisor, Site Engineer, and Project Manager. Furthermore, qualitative data analysis is performed to obtain the mean and standard deviation to determine dominant activities as waste and plot the mean value of frequency and impact to find out high risk activities as waste.

\section{B. Types and Data Collection Methods}

The types of data used in this study are:

- Primary data in the form of structured interviews with the Site Manager, Supervisor, Site Engineer, and Project Manager.

- Secondary data are data obtained from journals, preceding references and research on material waste.

\section{RESEARCH RESULT}

\section{A. Identification of Sources and Causes}

Waste identification contains waste variables and variables that cause waste from journals, observations and interviews. Identification of waste is done with the aim to integrate waste obtained from the literature with the results of observations and interviews. The occurrence of the remaining construction material can be caused by one or a combination of several sources and causes. Waste identification is also based on research conducted by Gavilan and Bernworld [2], which distinguishes the remaining sources of construction material into six categories: (1) design; (2) material procurement; (3) material handling; (4) implementation; (5) residuals; (6) others. The results of the research by Bossink and Brouwers [3] in the Netherlands, concluded that the sources and causes of the occurrence of the remaining construction materials based on the categories made by Gavilan and Bernworld [2] can be seen in the appendix. Based on previous studies from several journals and derived from the results of research by Gavilan and Bemold [2]. In determining the questionnaire variables, the variables are divided into two, namely the waste variable and the variable that causes waste. The waste variable aims to find out the frequency of waste that often occurs and the effect / impact of waste effects, while the variable causes waste to find out what factors most often cause waste. Analysis of research data in the form of data validity test, data reliability test, and Weighted Mean Score analysis. In this study data collection methods were used, namely observation, interviews and questionnaires. Observations were made on resource persons / experts in the field of civil engineering PNB who are experienced in handling building construction projects and research on building materials. The interviews were conducted on representatives of experienced contractors in the building construction project in the Badung area and surrounding areas such as the project manager, site manager, site engineer, field implementer, field supervisor. Questionnaires were distributed to 9 different contractors in Badung Regency and surrounding areas as many as 20 questionnaires. To facilitate respondents in filling out the questionnaire, the questionnaire is given a Likert Scale range, which is the range of the frequency of occurrence of waste, the impact of waste generated, and factors that often lead to waste from the smallest to the largest/most frequent.

Based on previous studies from several journals and sourced from the results of research by Gavilan and Bemold [2], the identification of waste can be seen in the following table:

TABLE I. SOURCE AND CAUSES OF WASTE

\begin{tabular}{|c|l|}
\hline No & \multicolumn{1}{|c|}{ Cause of Material } \\
\hline A & Human Resources \\
\hline 1 & Lack of labor skills \\
\hline 2 & Improper distribution of labor \\
\hline 3 & Lack of supervision in the site \\
\hline 4 & The number of foremen is not according to needs \\
\hline 5 & Low quality subcontractors \\
\hline 6 & Inexperienced supervisor \\
\hline 7 & Discipline of workers \\
\hline B & Management \\
\hline 1 & Inaccurate planning and scheduling \\
\hline 2 & The information provided is not clear or wrong \\
\hline 3 & Lack of coordination between the parties involved in the project \\
\hline 4 & Delay in decision making \\
\hline 5 & Selection of improper / inappropriate construction methods \\
\hline C & Design \\
\hline 1 & Unclear specifications \\
\hline 2 & Unclear work picture \\
\hline 3 & Slow revision and distribution of images \\
\hline 4 & Design changes \\
\hline 5 & Inappropriate design with field conditions \\
\hline 6 & Incomplete contract document \\
\hline D & Material \\
\hline 1 & Material quality is not accordance with specifications \\
\hline 2 & Material is not well packaged \\
\hline 3 & Material handling that is careful at the time of dismantling \\
\hline 4 & Scheduling the delivery of material to the site is lacking in \\
\hline
\end{tabular}




\begin{tabular}{|c|l|}
\hline No & \multicolumn{1}{|c|}{ Cause of Material } \\
\hline & planning \\
\hline 5 & Material damage due to transport to / at the project site \\
\hline 6 & Improper material storage causes damage \\
\hline E & Implementation \\
\hline 1 & Excessive overtime \\
\hline 3 & Poor equipment maintenance \\
\hline 4 & Tool planning is not in accordance with the need in the site \\
\hline 5 & Old / outdate equipment \\
\hline 6 & Structuring the field plan that is less effective and efficient \\
\hline 7 & The use of the wrong material needs to be replaced \\
\hline 8 & Inaccurate field measurement resulting in excess volume \\
\hline F & Residual \\
\hline 1 & The remaining cutting material can no longer be used \\
\hline 2 & Error when cutting material \\
\hline 3 & $\begin{array}{l}\text { Material order error, because they do not master the } \\
\text { specifications }\end{array}$ \\
\hline 4 & Poor packaging \\
\hline 5 & Remaining material due to the use process \\
\hline $\mathbf{G}$ & External \\
\hline 1 & Inadequate location conditions \\
\hline 2 & Weather \\
\hline 3 & Damage / loss by other parties \\
\hline
\end{tabular}

Forms and results of questionnaires for waste variables that have been processed with Microsoft Excel and tested for validity and reliability, with limits on the frequency of waste generation as follows Never (0 times), Rarely (1-2 times), Sometimes (3-4 times), Often (5-6 times), and very often (> 6 times), while for the effect / effect limit based on the percentage value of the loss on the unit price per-job as follows: None (0\%), Small (0.1-0.5\%), Medium (0.51-1\%), Large $(1.1 \%-2 \%)$, and Very Large $(>2 \%)$.

From the results of the analysis it can be seen that the waste that often occurs in a project is due to "lack of skilled labor" with the highest mean value of 4.22 , and the one that has the greatest impact on the percentage of losses to the loss of unit price per job in building projects in Badung district is " material quality does not match specifications "with the highest mean value of 1.51 .

\section{B. Waste Risk Matrix}

The purpose of this matrix is to find out the amount of waste risk in building projects in Badung Regency and its surroundings based on the frequency of occurrence and the effect / impact effects. To find out the size or the extent of the risk, a rating scale is made, with the following limits: Scale 1 (frequency Never and impact None, interval mean 1.00-1.80 and 0.01-0.25), Scale 2 (Rarely frequency and Small impact, interval mean value 1.81-2.60 and 0.26-0.50), Scale 3 (frequency Sometimes and Medium impact, mean interval 2.61-3.40 and 0.51-1.25), Scale 4 (Frequent frequency and Large impact, mean interval 3.41-4.20 and 1.26-1.75), and Scale 5 (Very Frequent frequency and Very Large impact, interval mean value 4.21-5.00 and 1.75-2.00).

From the results of the analysis can be described the correlation between the frequency and impact of the effect of waste in a waste risk matrix based on Health and Risk Assessment Templates from the University of Newcastle,
Australia, adapted from AS / NZS 4360: Risk Management can be seen in the following graph:

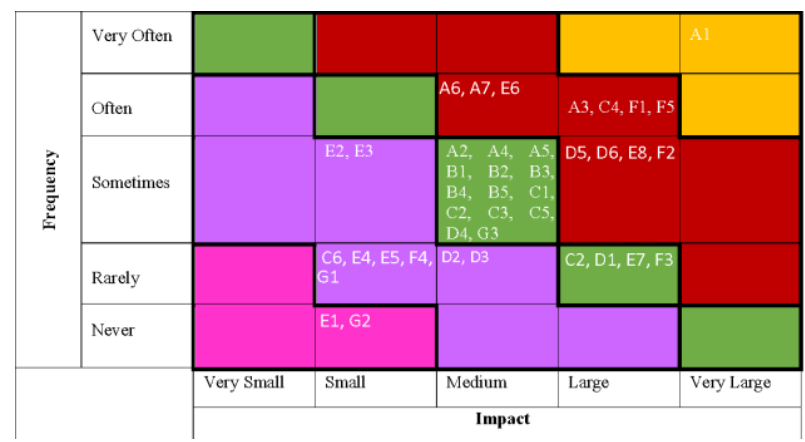

Fig 1 Risk Matrix of Waste on Building Projects

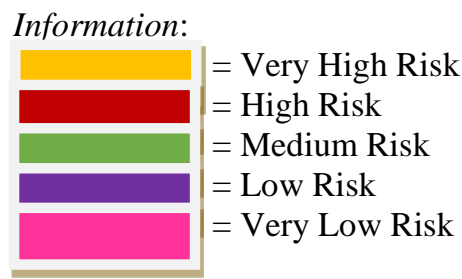

Explanation of waste risk matrix is as follows: Very Low (the effect is very small on project implementation), Low (the effect is small or medium so that it can have a slightly serious effect), Medium (the effects are quite serious so it requires a little/enough rework), High (serious disruption to project implementation and corporate finance so that it must be addressed as soon as possible), and Very High (very serious disruption to project implementation and corporate finance).

\section{Waste Material Mitigation Action}

Actions taken to reduce the impact of risk arising from the identified risks are called risk mitigation measures. Mitigation actions in this study are summarized based on the results of questionnaires filled out by respondents and from references related to effective and efficient project management. Mitigation actions that can be carried out to minimize risks are very high and high risks of project activities in this research as a cause of waste occurrence are as follows:

- Handling the causes of waste sourced from human resources by recruiting skilled and experienced workers who are certified, applying discipline in the field by carrying out routine or periodic supervision to ensure that the work is carried out in accordance with specifications. Field supervisors who are experienced and have high integrity towards the quality of work are very necessary to reduce reworking due to lack of skill and indiscipline of the workforce.

- The handling of the causes of waste comes from design, namely by preparing experts in the project organization structure needed according to the 
characteristics of the project so that errors in the analysis can be avoided.

- Handling the causes of waste from material sources, namely ensuring that selected suppliers of building materials are also concerned with the quality and storage of material in the field in accordance with the type and nature of the material so as to maintain the quality of the material before its use.

- The handling of the causes of waste comes from implementation is by designing effective and efficient site facilities from several alternative plans to obtain an optimal traveling distance and safety index. Inaccurate volume measurements in the field can be avoided by always checking and rechecking the measurement results so that excessive volume calculations can be avoided.

- Handling the causes of waste originating from residuals due to residual cutting that can no longer be used can be anticipated by using software so that the remaining unused cuts can be minimized. Errors at the time of cutting in addition to the skills of the workforce itself also required detailed and clear work drawings and special supervision by the head of the craftsman or foreman. Whereas the rest of the material because the usage process can be prevented by arranging a plan of material needs that are precise and accurate by the experts before the process of carrying out the work begins.

\section{CONCLUSION}

The conclusions that can be taken in this study are as follows:

- Activity as a potential factor that causes waste material to occur in building construction projects in Badung regency, which most often occurs is "lack of skilled labor" with a mean value of 4.22 while the activity as the causative factor that has the greatest impact is "quality of material not according to specifications "with a mean value of 1.51 .

- From the waste risk matrix it is found that "lack of skilled labor" is included in the category of very high waste risk due to the frequency that often occurs so that it is a very serious disruption to project implementation and corporate finance.

- Mitigation actions to deal with material waste that occur in the field can be done by preparing appropriate project implementation plans including site facilities plans and project and project organization resources that are in accordance with the characteristics of the project itself so that calculation errors and analysis of design changes can be prevented.

\section{ACKNOWLEDGMENT}

This research was supported by Bali State of Polytechnic, Institutional Grant 2018. We thank our colleagues from Civil Engineering Departement who provided insight and expertise that greatly assited the research.

We thank to the research team [Kristinayanti,ST.,MT, Wiwin Andayani,ST.,MT, Putri Indrayanti, ST.,MT] who help analyze the researh and to our students [Wulandari, Moh.Avif, Pramiditha, Krismayanti, Dwi Astari, Wahyu Adiatmika] and special thank to Internship Research of France Student [Clara Toussaint, Thomas Dauphin] who help conduct surveys and collect data. And thanks to the research support team [Prami, Priti, Mirah] as well who helped in reporting process.

We would also like to show our gratitude to management staff of the project of building in Badung Regency who gives us data location and characteristic of the project which we use as case studies.

\section{REFERENCES}

[1] J.R. Illingworth, Waste in the construction process, 1998

[2] R.M. Gavilan, and L.E Bernold, "Source evaluation of solid waste in building construction," J. of Construction Engineering and Management, vol. 120, pp. 536-552, September 1994.

[3] B.A.G. Bossink, and H.J.H. Brouwers, Construction Waste Quantification and Source Evaluation. 1996.

[4] A. Enhassi, "Materials Control and Waste on Building Site," Building Res. and Information, vol. 24, pp. 32-34, 1996.

[5] C.T. Farmoso, L. Soibelman, C.D. Cesare, and E.L. Isatto, "Material waste in building industry: main causes and prevention," J. of Construction Engineering and Management, vol. 128, pp. 316-325, August 2002.

[6] A.P. Wiguna, and H. Iriana, "Analysis of Material Waste Handling in Housing Projects in Surabaya," National Seminar on Application of Regional Infrastructure Technology, Surabaya, 2009.

[7] G. Rubina, Construction Waste Minimization Good Practice Guide, Welsh School Arch, 2004.

[8] A. Horsley, C. France and B. Quartermass, "Delivering Energy Efficient Buildings: A Design Procedure to Demonstrate Environmental and Economic Benefits," J. of Construction Management and Economics, vol. 21, p. 345, 2003.

[9] J. Watuka and E.M. Aligula, "Sustainable Construction Practices in the Kenyan Construction Industry: The Need for a Facilitative Regulatory Environment, Proceedings of the CIB W107 $1^{\text {st }}$ International Conference: Creating a Sustainable Construction Industry in Developing Countries," vol. 1, Stellenbosch, South Africa, November 2002.

[10] S. Alwi, K. Hampson, and S. Mohammed, Waste in The Indonesian Construction Projects, 2004.

[11] C. S. Poon, A.T.W. Yu, S. W. Wong, and E. Cheung, "Management of construction waste in public housing projects in Hong Kong," J. Construction Management and Economics, vol. 22, pp. 675-689, 2004.

[12] R.A. Begum, C. Siwar, J.J. Pereira, and A.H. Jaafar, "Attitude and Behavioral Factors in Waste Management in the Cobstruction Industry of Malaysia," Resources, Conservation and Recycling, vol. 53, pp.321328, April 2009.

[13] P. Guthrie, and H. Mallet, Waste Minimisation and Recycling in Construction, A Review CIRIA Special Publication 122, 1995.

[14] C. Poon, and L. Jaillon, A Guide for Minimizing Construction and Demolition waste at the Design Stage, 2002.

[15] C. Tatum, J. Vanegas, and J. Williams, Constructability Improvement Using Prefabrication, Pre-assembly and Modularisation, Technical Report 297, Cosntruction Industry Institute, Stanford, USA, 1986. 